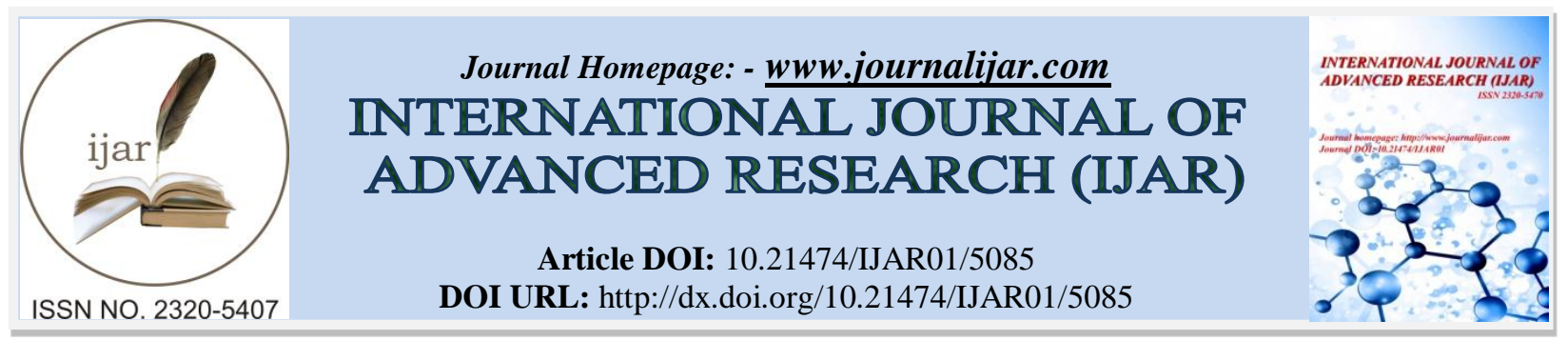

RESEARCH ARTICLE

\title{
EFFECT OF ANULOMA VILOMA PRANAYAMA ON PRIMARY DYSMENORRHOEA IN YOUNG FEMALES.
}

\section{Sayam Subhash ${ }^{1}$, Krishnamoorthi $\mathbf{P}^{2}$ and Pramod Thomas ${ }^{3}$.}

1. Department of Physiology, Dr. Somervell Memorial CSI Medical College, Karakonam, Trivandrum, Kerala, Pin - 695504.

2. Department of Physiology, Kasturba Medical College, Manipal University, Manipal, Karnataka, Pin - 576104.

3. Department of Community Medicine, Believers Church Medical College, Thiruvalla, Kerala, Pin - 689621.

\section{Manuscript Info}

Manuscript History

Received: 06 June 2017

Final Accepted: 08 July 2017

Published: August 2017

Key words:-

primary dysmenorrhoea, Anuloma

Viloma Pranayama, yoga

\section{Abstract}

Objective: To assess the clinical efficacy of yoga as an alternative therapy for primary dysmenorrhoea.

Methods: 151 female students, 18-25 years old, with primary dysmenorrhoea were selected and assigned to test $(n=75)$ and control groups $(\mathrm{n}=76)$. Numerical Rating Scale (NRS) and Visual Analogue Scale (VAS) for pain were administered at baseline and after one menstrual cycle or 30 days. The test group was subjected to Yoga intervention. The control group did not receive any intervention during one menstrual cycle or 30 days duration.

Results: Significant reduction in the perceived pain after yoga intervention as compared to control groups was observed. $1 \%$ of the test group reported complete pain relief using NRS scale. There was also a decrease in number of subjects with severe pain from 8 to 1 after the yoga intervention. Compared to control group, students with yoga intervention demonstrated significant improvement in perceived pain $(\mathrm{P}<0.01)$.

Conclusion: With a regular practice of yoga, that is Pranayama, the pain of dysmenorrhoea was controlled, indicating the benefits of anuloma viloma pranayama in primary dysmenorrhoea. Hence, training for yoga should be done at school level and recommended for regular use in their homes.

Copy Right, IJAR, 2017,. All rights reserved.

\section{Introduction:-}

Dysmenorrhoea is a cyclical pelvic pain associated with menstruation. It is cramping, lower abdominal pain occurring just before and/or during menstruation, lasting for 1-3 days, usually commencing soon after menarche once regular ovulation is established (Ee C, Pirotta M,2006).

It has been observed that approximately 50-90\% of the adolescent and young working women suffer from dysmenorrhoea. Dysmenorrhoea leads to increased absenteeism in schools and workplace and lesser quality of life in women (Smith RP and Kaunitz AM, 2013, Shabnam Omidvar,Khyrunnisa Begum, 2011). In India, none of the studies reported the prevalence of dysmenorrhoea at national level. However, Omidvar (2011) conducted a survey 
among college students from Mysore in Karnataka state reported the prevalence as 78.2\% (Shabnam Omidvar and Khyrunnisa Begum, 2011).

Several treatment modalities like medications and home remedies being used by primary dysmenorrhoeics are either not effective or produces long term side effects (Chaudhuri A and Singh A,2012). Simple lifestyle modifications such as yoga may help in alleviating pain during menstruation (Sivananda SS, 1978). However, no study till date has been done to prove the effect of anuloma viloma pranayama on dysmenorrhoea.

Anuloma viloma is one of the eight varieties of Pranayama. Anuloma means 'Cyclic' and Viloma means 'anticyclic' (Sivananda SS, 1978). Anuloma Viloma pranayama is seen to 'balance' both the right and left brain as was evidenced with EEG in one study (Jr SA and Kuna M, 1994). It hence allows one to be calm and alert.

Yoga is proved to produce calmness which may alleviate irritability and allow them to carry out their normal daily activities (Rakhshaee Zahra, 2011). There is a paucity of research in the field of effects of pranayama, especially Anuloma Viloma Pranayama - the simplest among all others, on dysmenorrhoea that made us do this study. Present study assessed the effect of pranayama in yoga, on primary dysmenorrhoea.

\section{Material \& Methods:-}

The study was conducted over a period of 6 months, between October 2012 and April 2013 in the Department of Physiology, Kasturba Medical College, Manipal, India. Ethical approval has been obtained from the Institutional Ethics Committee (reference number: IEC 372/2012) and informed written consent was taken from all the participants.

There were a total of 151 young females, 18-25 years old, with primary dysmenorrhoea were selected through personal interview from undergraduate and postgraduate nursing and medical students of Kasturba medical college, Manipal. Participants were selected for either yoga intervention $(n=75)$ or to become control $(n=76)$, for a period of one menstrual cycle (can vary from 21 to 35 days from person to person) according to inclusion and exclusion criteria (given below) (D C Dutta, 2013).

The subjects willing for Yoga intervention were asked to sit in a hall which was ambient, well-ventilated, quiet room at room temperature, daily for a session of 15 minutes, in the morning before meals, during one menstrual cycle time period, from $3^{\text {rd }}$ day of the first menstrual cycle after enrolling into the study to the $3^{\text {rd }}$ day of the subsequent menstrual cycle. Initially, participants in the test group were trained for Anuloma Viloma Pranayama by the yoga expert and they practiced in the following days.

The yoga practice was in such a way that, subjects were seated in Sukhasana and right hand held in Vishnu mudra. They were asked to close their eyes and concentrate on their breathing via their nostrils. Anuloma Viloma pranayama (alternate nostril breathing) consists of only Puraka (inspiration), Rechaka (expiration) at a ratio of 1:1 and gradually increased to 1:2 initially for first two weeks after which Puraka, kumbhaka (retension) and Rechaka was performed for next 2 weeks at a ratio of 1:4:2, performing kumbhaka for 16 counts.

Duration for each breath (inhalation or exhalation) varied in the first week. For the first three days, four seconds (period of completion for each breath), next two days, eight seconds and last two days, sixteen seconds was advised. However, only when one became comfortable with the given duration for each breath, was she allowed to advance her counts further.

During first week, Anuloma Viloma Pranayama was performed by closing right nostril with the right thumb and complete exhalation with left nostril for 4 counts, after which inhalation was done for 4 counts with left nostril. Then the left nostril was closed using the right ring and small fingers and thumb closing the right nostril was released. The same 4 counts of exhalation first and then inhalation for 4 counts was performed this time through the right nostril. This entire process of pranayama was performed for 15 minutes. Time for each breath was extended till exhalation for 16 seconds and inhalation for 16 seconds was performed by the end of the first week. During the second week, ratio was changed and exhalation was for twice the time of inhalation. Anuloma Viloma pranayama was carried out with exhalation (32 seconds) and inhalation (16 seconds). 
In the third and fourth week, Anuloma viloma pranayama with retention or Nadi Shodhanam with kumbhaka was taught. Inhalation for 4 counts via the left nostril, retention for 16 counts by closing both nostrils and exhalation for 8 counts via right nostril by removing the thumb was performed. Again inhalation for 4 counts via the right nostril, retention for 16 counts and exhalation for 8 counts via the left nostril was performed. This makes one complete cycle of anuloma viloma pranayama. It was performed for 15 minutes (Swami Rama 2012, Yogi Svatmarama).

\section{Inclusion criteria:-}

Under graduate and post graduate medical and nursing students with regular menstrual cycles of normal duration were enrolled.

\section{Exclusion Criteria:-}

Smokers, alcoholics, unable to follow exercise regime, those suffering from any chronic disease conditions like allergy, arthritis, hypertension, migraine, epilepsy and diabetes or taking any medications like pain killers or hormonal tablets were excluded from the study. In addition, those already practicing any kind of yoga or exercises were excluded from the study.

\section{Instruments Used:-}

1. Semi structured Questionnaire/ Performa: A semi structured questionnaire was used to collect the personal information on demographic and physiological details. The Performa was filled by the investigator after personal interview with each subject.

2. Their pain during menstruation was recorded using pain scales; Visual Analogue Scale (VAS) and Numerical Rating Scale (NRS).

VAS: The Visual Analogue Scale is a horizontal line of length $10 \mathrm{~cm}$, with no interrupted markings, which starts with a smiling face (indicating no pain) and ends with sad face (indicating worst face).

NRS: The Numerical Rating Scale consists of a range of numbers from 0-100 with markings at intervals of 10.

The subject selects and marks the approximate point on the VAS and approximate number on the NRS scale; 0 indicates 'No pain' and 100 indicates 'Worst Possible pain'(MJ H et al, 2011).

VAS and NRS is also categorized into four grades - 'no pain': scaled as 0, 'mild and tolerable pain': scaled as 1030, 'moderate and seriously disturbing pain': scaled as 40-60 and 'severe and unbearable pain': 70-100. Two pain scales where used to minimize the errors inherent in each of them.

\section{Assessment:-}

First baseline recording of pain using VAS and NRS were performed on the third day of menstrual cycle and second recording was done on the $3^{\text {rd }}$ day of the subsequent menstrual cycle.

\section{Statistical Analysis:-}

Data entered in to MS excel and descriptive measures (mean (SD) or proportions) were calculated. Age, Menarche, VAS and NRS scores at base line and VAS and NRS scores at the end of the study were compared between yoga intervention group and control group using independent t-test. In addition, VAS and NRS scores were compared between baseline and at the end of the study using paired t-test for both the study groups (yoga intervention group and control group). A p- value $<0.05$ was considered as statistically significant. SPSS version 16 was used.

\section{Results:-}

There were a total of 151 participants enrolled in to the study from undergraduate and post graduate medical and nursing students. Mean age group and age at menarche for interventional and control groups are 21 years and 13 years respectively. The baseline characteristics Age, Menarche, VAS and NRS scores were compared between yoga intervention group and control group using Independent Student's $t$ - test and found to be not significantly different and comparable. Chronological age $(\mathrm{p}$-value $=0.909)$ and age at menarche $(\mathrm{p}$-value $=0.952)$, VAS $(p-v a l u e=0.861)$, NRS (p-value $=0.811)$ were similar in both groups (Supplementary table 1$)$. 
Table 1:- Showing the pain intensity before and at the end of the study in both control and test groups and also the P values obtained with paired Student's t- test.

\begin{tabular}{|c|c|c|c|c|c|c|}
\hline $\begin{array}{l}\text { Outcome } \\
\text { variable }\end{array}$ & Group & $\mathbf{N}$ & Mean & SD & t- value & p- value \\
\hline \multirow[t]{2}{*}{ VAS } & Pre Test & 75 & 41.84 & 20.57 & \multirow[b]{2}{*}{2.013} & \multirow[b]{2}{*}{0.048} \\
\hline & Post Test & 75 & 37.81 & 18.93 & & \\
\hline \multirow[t]{2}{*}{ VAS } & Pre Control & 76 & 41.49 & 12.44 & \multirow[b]{2}{*}{-2.235} & \multirow[b]{2}{*}{0.028} \\
\hline & Post Control & 76 & 45.40 & 15.95 & & \\
\hline \multirow[b]{2}{*}{ NRS } & Pre Test & 75 & 40.27 & 20.60 & \multirow[b]{2}{*}{9.224} & \multirow[b]{2}{*}{0.0001} \\
\hline & Post Test & 75 & 30.13 & 19.10 & & \\
\hline \multirow[b]{2}{*}{ NRS } & Pre Control & 76 & 40.533 & 11.14 & \multirow[b]{2}{*}{1.395} & \multirow[b]{2}{*}{0.167} \\
\hline & Post Control & 76 & 39.20 & 17.76 & & \\
\hline
\end{tabular}

In the test group, baseline value of VAS declined from 41.84 to 37.81 by the end of the study and baseline value of NRS declined from 40.27 to 30.13 by the end of the study (Table 1). In the control group, the baseline value of VAS has increased from 41.49 to 45.40 by the end of the study ( $\mathrm{p}$-value=0.028).

Figure 1:- VAS Scores according to pre and post based on cases and control

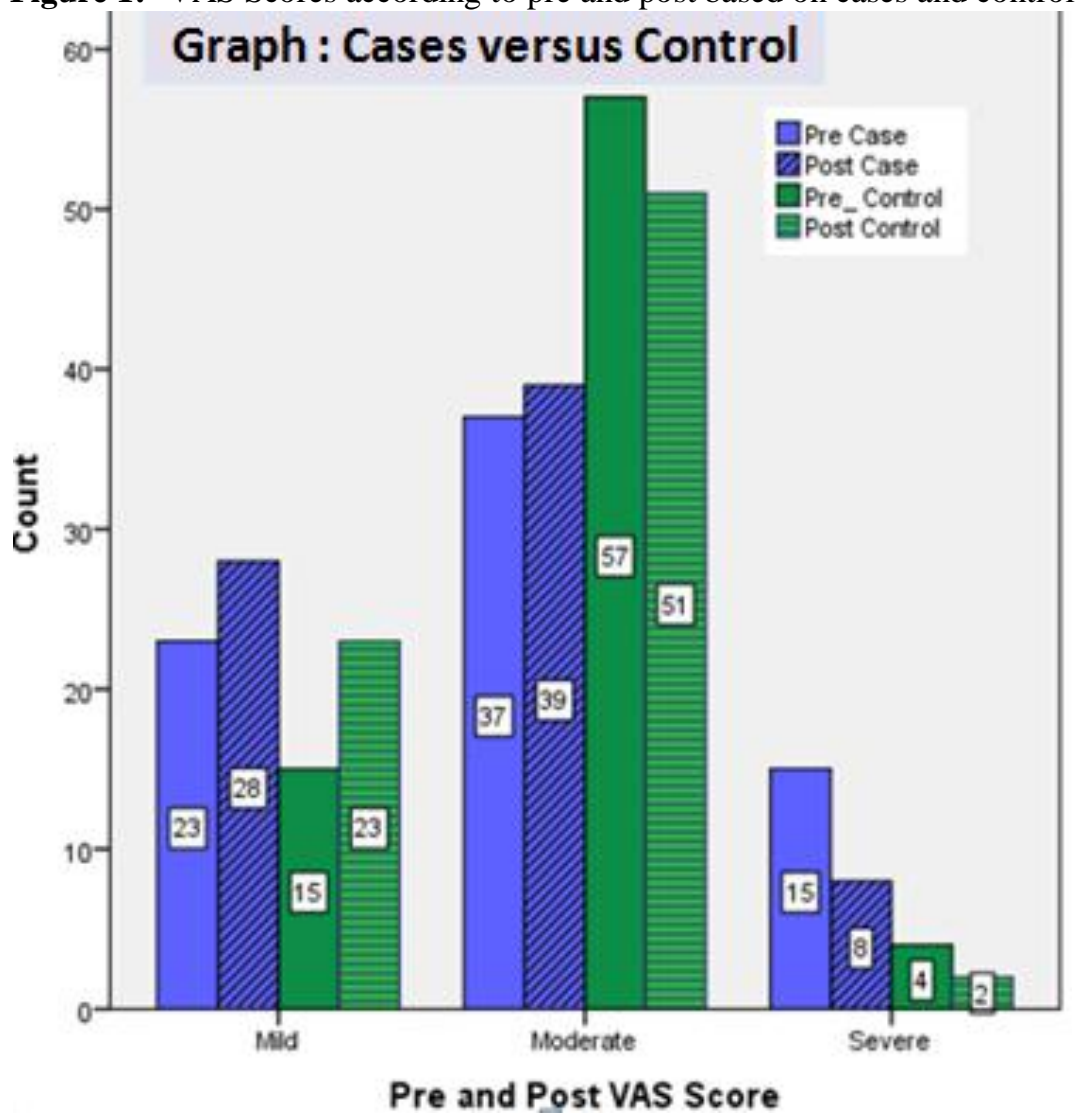

Figure 1 and Figure 2 pointed out different levels of severity of the dysmenorrhoerric pain among the cases and control participants assessed by VAS and NRS pain scales. Total 151 participants ( 75 cases and 76 controls) were shifted to different levels of pain post yoga. 


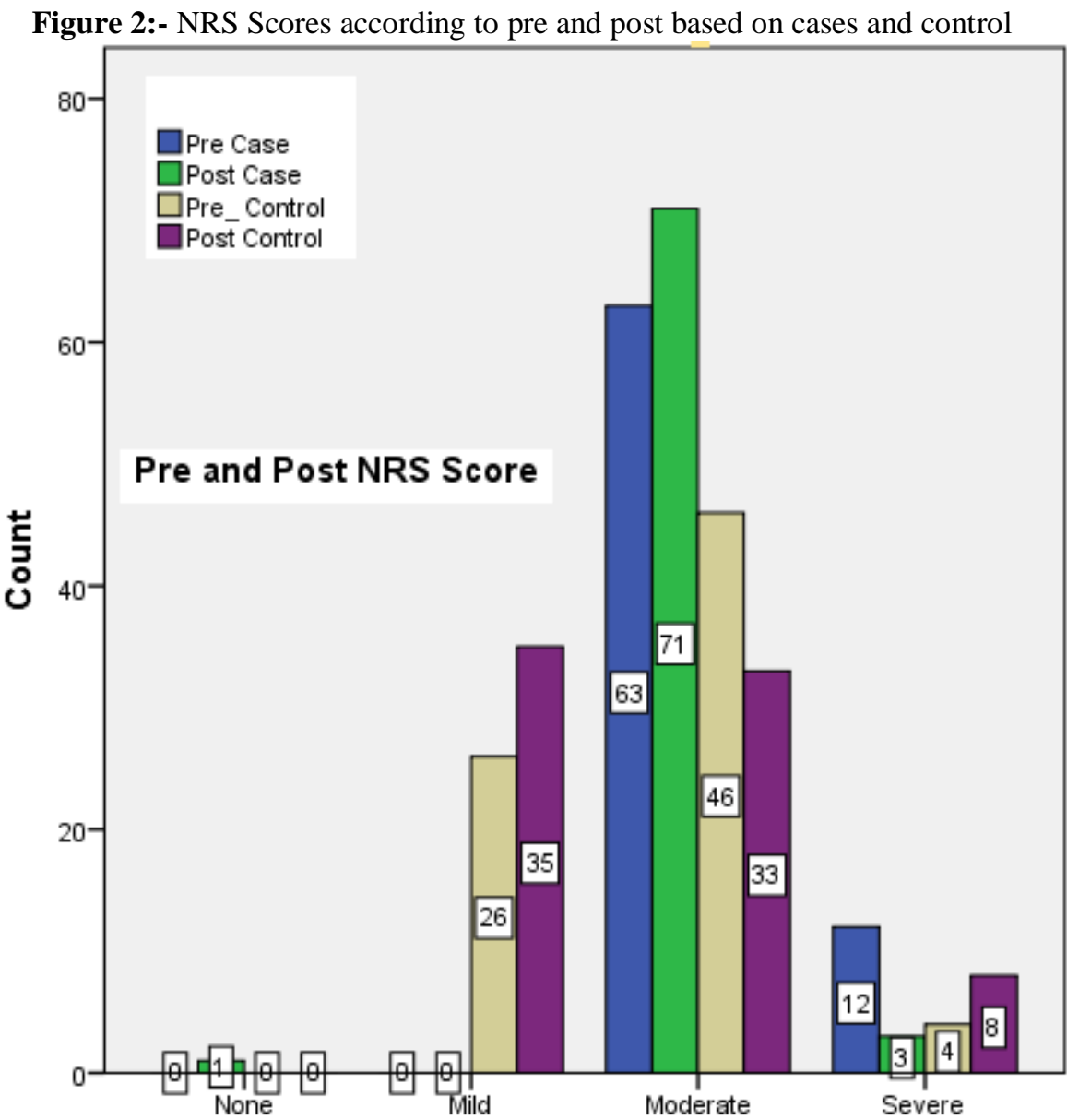

In addition, we calculated the number of participants shifted across various pain levels as below. Using VAS pain scores, among the 75 participants in test group, 15 were severe at baseline and 11 of them became moderate and 4 remained same after the intervention program. Similarly, among the 37 having moderate pain, 22 remained the same, 11 became mild and 4 became severe $($ Chi_value $=25.150$, $\mathrm{p}$-value $=0.0004)$.

Using VAS pain scores, among the 76 participants in control group, 4 were severe cases at baseline and 3 became mild and 1 became moderate. Similarly, among the 57 moderate, 9 became mild, 2 became severe and 46 remained moderate. Among the 15 mild, 4 became moderate and 11 remained the same. ( Chi_value $=24.249$, p-value $=0.0001$ ) Using NRS pain scores, among the 75 participants in test group, 63 were moderate at baseline and continued to be the same in the post test. Similarly, among the 12 severe, 1 became mild, 8 became moderate and 3 remained the same (Chi_Value - 22.18, p-value-0.0001) (Table not given).

Using NRS pain scores, among the 76 participants in control group, 4 were severe and 3 became moderate and 1 remained the same. Similarly, among 46 moderate, 6 became severe, 25 remained and 15 became mild. Also, among the 26 mild, 1 became severe, 5 became moderate and 20 remained the same. (Chi_Value - 16.413, p-Value- 0.003)

Since VAS and NRS scales showed similar results, it can be pointed out that anuloma viloma pranayama is beneficial in reducing the menstrual pain in primary dysmenorrhoeics.

\section{Discussion:-}

Primary dysmenorrhoea is experienced with varied pain intensity- it may range from mild to severe (causing inability to perform daily activities). Medications and home remedies are found to be not effective in reducing this pain and may also produce side effects on prolonged use (Chaudhuri A and Singh A, 2012). Hence, in the current 
situation, a simple lifestyle change, such as including pranayama, may help in reducing the pain and improve quality of life in primary dysmenorrhoeics for all levels of pain intensity.

In the present study, we observed a significant reduction in pain intensity reflected by decrease in the average pain scores and a shift from severe and moderate pain to mild pain in the test group at the end of the study when compared to control group. After yoga, using VAS, a shift is noted from moderate and severe to mild (37\%) whereas in the control group only $30 \%$ were in the mild category (Figure 1).

After yoga, the number of dysmenorrhoeics reporting with none pain using NRS has increased from $0 \%$ to $1 \%$, while the number of participants experiencing severe pain has reduced from $16 \%$ to $4 \%$. . In contrast, none reported with complete pain relief in the control group and there was an increase in the number of dysmenorrhoeics suffering with severe pain (Figure 2). Using NRS, there was no change in the number of participants in moderate pain post yoga. However, in the control group there was a noticeable shift from moderate to severe (61\% to $8 \%$ ).

There was also a significant reduction in average pain scores with VAS (P value $<0.01)$ and with NRS (P value $<0.0001)$ in the test group by the end of the study. However, the control group showed an insignificant increase in average pain scores (Table 1). These findings are in line with previous studies, showing a significant reduction in pain scores ( $\mathrm{P}$ value $<0.0001$ ) and also a shift towards none and mild categories (Rakhshaee, Zahra 2011, Nag U and Kodali M, 2013, Usha N and Madhavi K,2013).However, these studies have used a variety of yoga techniques (asanas, breathing techniques and meditation) combined together to bring about reduction in pain scores.

Our results are comparable with Rakhshaee Z, who suggests that this reduction in pain intensity could be due to the effect of yoga therapy on influencing the components of pain such as tension and fear. Awareness and controlled breathing, especially the exhalation is the relaxation part of the yoga therapy that reduces tension and the suggestions in yoga therapy reduces the fear component (Rakhshaee, Zahra,2011).

In this study, the controlled breathing might have produced a relaxation response in the participants to decrease their pain intensity. Also, the awareness and concentration required to keep the timing of breaths could have induced the participants into a meditative state and so increased the threshold to pain. Budding attention in alternative and complementary medicine has led to the appreciation of yoga in the world and acknowledges its medical benefits when presented with scientific evidence. This study contributes to the development of knowledge in gynecological field about how female adolescents with dysmenorrhea can manage themselves.

Till to date, to the best of our knowledge, the published data regarding effect of a single pranayama on primary dysmenorrhoea is found to be lacking and yet to be established. The similar studies we have found have used yoga as part of an exercise program to increase general health, reduce stress, improve flexibility and strengthening of muscles, and used to alleviate chronic pain (Carlson K.J. et al, 1996).

The present study aimed to assess the subjective feel of the participants in reduction of pain or irritability. It is not identified whether there is any actual reduction in pain and irritability or whether the tolerance of the participant is increased by increasing the inherent level of calmness by the intervention of yoga. The obtained data is collected from young female volunteers with moderate to severe pain, enrolled in the yoga program and those with mild to moderate pain enrolled in the control group, as this study was done on a voluntary basis. This has led to a natural bias and is a limitation of the study.

Finally, comparisons of pranayama, meditation as well as other varieties of asanas on primary dysmenorrhoeics to understand which aspect of yoga is effective in alleviating pain may be suggested for future study.

\section{Conclusion:-}

The present study has demonstrated the efficacy of practicing Anuloma Viloma pranayama on pain intensity in dysmenorrhoeics during menstruation. As dysmenorrhoea is mainly a problem in younger age group, the young female adults may be motivated to include a simple-to-learn, noninvasive, safe and cost-effective pranayama especially a single practice of yoga: Anuloma Viloma pranayama - in their daily life, to lessen the pain intensity in dysmenorrhoeics. 
The practice of Anuloma Viloma pranayama regularly for a short period of one menstrual cycle of about 30 days, has beneficial effects in relieving dysmenorrhoeic pain. Compliance to yoga may be improved by including yoga classes into college curriculum and awareness about it as a therapy for menstrual pain may be emphasized by the medical professionals.

Conflict of interest: The authors declare that they have no conflict of interest

\section{References:-}

1. Carlson K.J, et al.(1996): The Harvard Guide to Women's Health. Harvard University Press Cambridge.

2. Chaudhuri A, Singh A.(2012): How do school girls deal with dysmenorrhoea? J Indian Med Assoc. 110(5):287.

3. D C Dutta.(2013): Textbook of Gynaecology including contraception. Sixth edition: New Central Book Agency(P) ltd: 178

4. Ee C, Pirotta M.(2006): Primary dysmenorrhoea--evidence for complementary medicine. Aust Fam Physician. 35(11):869.

5. Jr SA, Kuna M. (1994): EEG changes during forced alternate nostril breathing. Int J Psychophysiol. 18(1):75-9.

6. MJ H, Fayers P, et al.(2011): Studies comparing Numerical Rating Scales, Verbal Rating Scales, and Visual Analogue Scales for assessment of pain intensity in adults: a systematic literature review. J Pain Symptom Manage. 41(6):1073-93. DOI: 10.1016/j.jpainsymman.2010.08.016.

7. Nag U, Kodali M.(2013): Meditation and Yoga as alternative therapy for primary dysmneorrhea. International Journal of Medical and Pharmaceutical Sciences. 17;3(7):39-44.

8. Rakhshaee, Zahra.(2011): Effect of three yoga poses (cobra, cat and fish poses) in women with primary dysmenorrhoea: A randomized clinical trial. J Pediatr Adolesc Gyneco. 24(4):192-96. DOI:10.1016/j.jpag.2011.01.059.

9. Shabnam Omidvar, Khyrunnisa Begum. (2011): Menstrual pattern among unmarried women from south India. J Nat Sci Biol Med. 2(2): 174-179.

10. Sivananda SS.(1978): The science of pranayama. Himalayas: The divine life society.10.

11. Smith RP, Kaunitz AM.(2013): Primary dysmenorrhoea in adult women: Clinical features and diagnosis [Online]. Uptodate. [Updated on: 2013 May 29, cited on: 10/9/14]. Available from: http://www.uptodate.com/contents/primary-dysmenorrhoea-in-adult-women-clinical-features-and-diagnosis

12. Swami Rama.(2012): Path of Fire and Light, Advanced Practices of Yoga. Seventh Printing. The Himalayan Institute Press. Allahabad (U.P), India.

13. Usha N, Madhavi K.(2013): Effect of yoga on primary dysmenorrhoea and stress in medical. IOSR Journal of Dental and Medical Sciences .4(1):69-73. e-ISSN: 2279-0853, p-ISSN: 2279-0861.

14. Yogi Svatmarama. Hatha Yoga Pradipika. Source of E-text: http:// sacredtexts.com. 54-55 